\title{
Information Needs and Information Seeking Behavior of Students at Higher Educational Institutes: With Special Reference to CINEC Maritime Campus
}

\author{
A. Pradeepa Udayangani de Silva ${ }^{1, *}$, P. Sandhamali Chandrawamsa ${ }^{2}$ \\ ${ }^{1}$ Faculty of Science, University of Kelaniya, Sri Lanka \\ ${ }^{2}$ Colombo International Nautical and Engineering College, Maritime Campus, Sri Lanka
}

Copyright $\bigcirc 2016$ by authors, all rights reserved. Authors agree that this article remains permanently open access under the terms of the Creative Commons Attribution License 4.0 International License

\begin{abstract}
This study investigates that information needs and information seeking behavior of students at higher educational institutes: with special reference to CINEC Maritime campus. Based on three objectives, the research was conducted. The main objective of this research is to identify the information needs of students in one of the leading higher educational institute in Sri Lanka. Other objectives are to study the information seeking behavior of students in various aspects, such as subjective needs, research needs other information needs and to study the user satisfaction and ICT application for seeking information. The key findings of the study indicate that $50 \%$ of students gather information for preparing their lecture notes. Not only that they collect information for updating their knowledge and having for discussions. CINEC Maritime campus library is the most frequently used place of the best access for information gathering by the students. $80 \%$ students expect their information in English medium. Using Information Technology (IT) is improved through students when they retrieve information for their information needs.
\end{abstract}

Keywords Information, Information Needs, Seeking Behavior, Maritime Students, Maritime Library

\section{Introduction}

Every person requires information to update their knowledge and fulfill any kind of purpose. In present, people even can't live without information. The reason for that, information has become inevitable need of people. However, the way of information searching is differ from person to person. Any kind of professions use any kind of information media to search information such as, library, personal collections, book stores, discussions/ conversations, consultation, and meeting/ Seminars/ Conferences/ Workshops \& IT based sources.
As such people used to use various kinds of information Medias. Not only professions, students also need to find information for preparing lecture notes, updating knowledge, preparing answers for questions, reading, thinking purposes, research works, observations and experiments, discussions and preparing for presentations. In here, their seeking behavior is also different. So that, there is a great need for the development of resources in the libraries in higher education institute and research centers in Sri Lanka. This research was conducted based on the problem that how students in higher educational institutes, satisfy their information needs.

Similarly, there are some significant, identified before implementation of the research. It can be listed out under below.

- This study will help to identify the information needs and information seeking behavior of students in CINEC Maritime campus. The results will use to improve the current information services of the library.

- This study is also very important to improve the resources in the library of CINEC campus.

- As well as, this study may help to identify unvalued services and resources in the library and remove them and replace new services and resources for student's necessities.

The main objective of this research is to identify the information needs of students in one of the leading higher educational institute in Sri Lanka (CINEC Maritime campus). Secondly this research is to study the information seeking behavior of students in various aspects. Such as,

- $\quad$ Subjective needs

- Research needs

- Other information needs

This research may also study the user satisfaction and ICT application for seeking information.

There are several researches related with information seeking behavior of higher education institutes. Below 
paragraphs described the literature of this research. Timpka, Ekstrom \& Bjurulf (1) undertook a qualitative study on information needs and information seeking behavior in primary health care in Sweden. 186 general practitioners were selected as sample for questionnaire survey. Among the key findings were that, $67 \%$ of supplying medical information is less satisfactory or unsatisfactory. $44 \%$ choice of information was achieved by therapy. However, personal libraries should be improved to fulfill current information needs of practitioners in primary health care. The reason for that practitioners in primary health care cannot depend on conventional medical library for their day to day information needs.

Ellis, Cox \& Hall (2) examined, Natural information seeking behavior of Social Scientists using a methodology (structural interviews) comparable with an earlier study which was done by Ellis (2). In here the findings indicate that no major differences were found in the information seeking behavior of the two groups through Social Scientists of the six standardized categories.

Illeperuma (3) has done a user study on Information needs and information gathering behavior of Pure Scientists in the University of Sri Lanka. The findings of the study confirmed that major purpose of information searching is to support research work of their subject disciplines and keep up with current developments. However the study revealed that periodicals / journals and abstract journals were the most widely used sources of information for current and every day information needs. As well as findings show that, the collections of library was not up to date.

Gamage (4) has done a research to fulfill the necessity of MSSc degree programme of University of Kelaniya on the topic of Information needs and information seeking behavior of Environmental Scientists in Sri Lanka. Ninety three (93) Environmental Scientists from academic, government and non-government institutions were selected as the sample. The findings reveals that, to achieve two objectives Scientists seek information. They are gain knowledge on current situations and to develop competence in their specialized areas. Majority of respondents ( $81 \%$ ) addicted to use their own libraries due to lack of facilities provided by their institutional libraries. As well as half from the sample prefer to use modern information technology to complete their information needs.

Zawawi \& Majid (5) have conducted a research on the information needs and seeking behavior of the IMR Biomedical scientists, Malaysia. The research used 84 biomedical Scientists. But researcher could collect 54 filled in questionnaires through 84 distributed questionnaires. The findings indicated that Biomedical Scientists addicted to variety of information sources to satisfy their information needs. Nevertheless most Scientists prefer to use printed materials than up to date digital channel of information for their information needs. On other hand respondents use e-mail as internet based information sources and applications. Two major difficulties were found through this research.
They are unavailability of materials and outdated collections of required information.

Jorosi (6) in another qualitative study, probed the information needs and information seeking behavior of SME managers in Botswana (SME- Small \& Medium sized Enterprises). Random sample was selected to distribute 400 questionnaires through eight sub sectors of the manufacturing industry. Findings shows that, 85 of respondents spent approximately 1-7 hours weekly to achieve customer, market and economic information.

Saleh \& Lasisi (7) used mainly questionnaire and several oral interviews to investigate the information needs and information seeking behavior of rural women in Borno state, Nigeria. The sampled population was eight local government areas of Borno state. Results revealed that highest percentage was recorded by Agricultural information needs. Education, Economy, Health, Political \& other information got lowest percentage. However, women in Borno state satisfies their information needs through orderly government \& its agents, Elite groups, relatives \& friends, market women \& nongovernmental organizations.

\section{Materials and Methods}

3000 students studied at CINEC Maritime campus were population of this study. According to random sample method $10 \%$ of students from the population were selected to distribute a detail questionnaire. Below graph shows that the population of the study (students in CINEC Maritime campus).

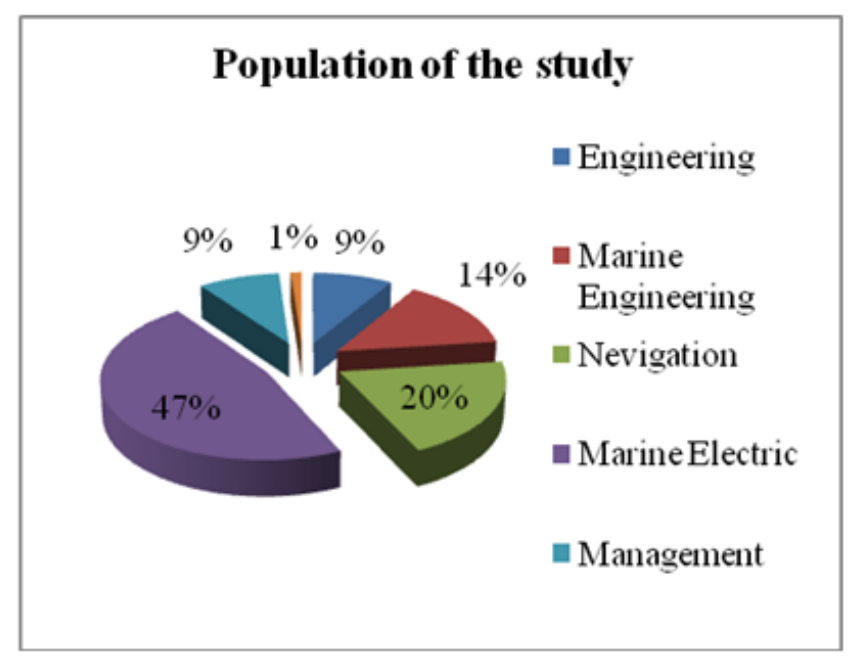

Figure 1. Population of the research

\section{Results}

After gathering primary data by using questionnaires, was analyzed by using SPSS (Statistical Package for Social Sciences). This paragraph describes about the research and analysis of information carried out for Information needs and 
information seeking behavior of students at CINEC Maritime campus. By using graphs, charts and tables, this chapter is presented the results of the research.

\subsection{Introduction for the Population and Sample}

3000 students were the population of this research and sample size was the $10 \%$ of the population. Figure 1 shows that the population of the research and figure $2 \& 3$ show that the sample of the research according to the subjects and sex.

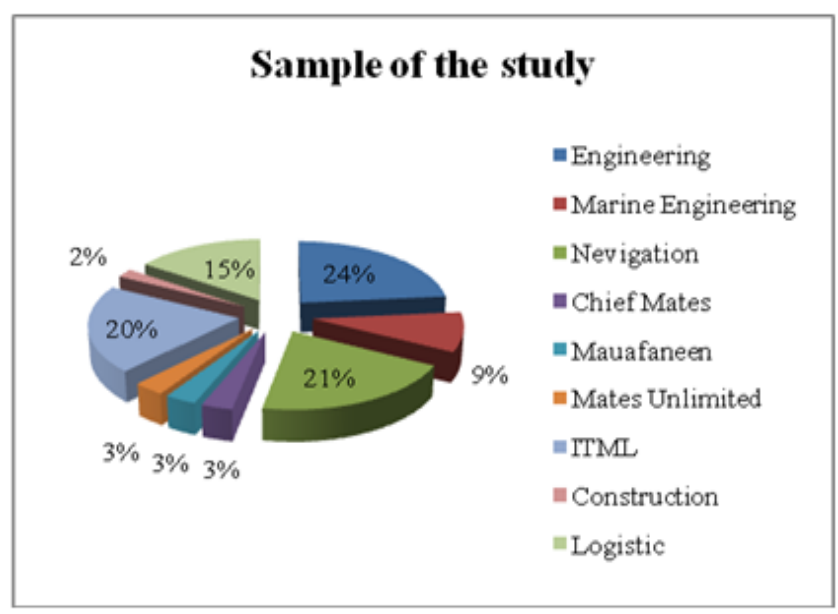

Figure 2. Sample of the study with subject areas

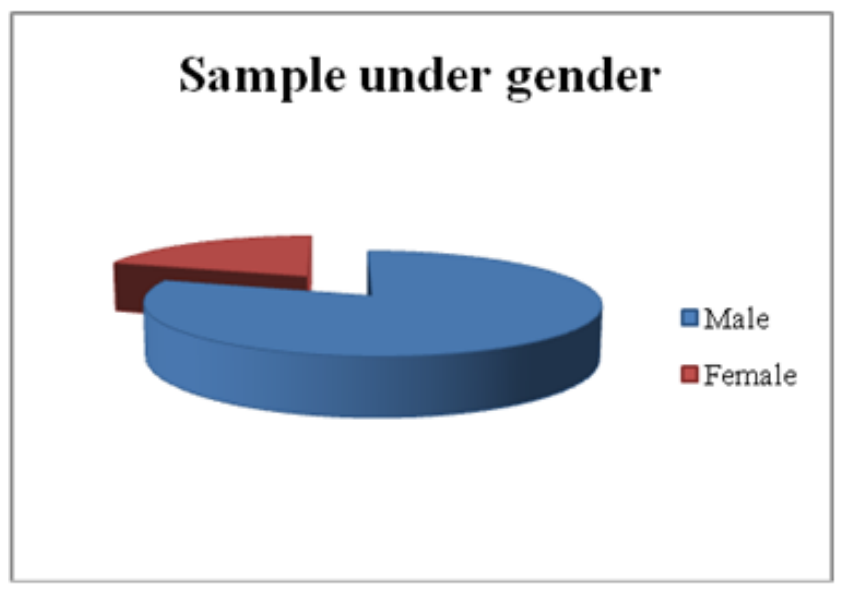

Figure 3. Sample of the study divided under sex

Figure 3 shows that the sample of the research is divided under sex category. Most of students are male and few of students are female in CINEC Maritime campus.

\subsection{Purpose of Gathering Information}

Figure 4 shows that $50 \%$ of the students collect information for preparing their lecture notes. Next highest percentage $(15 \%)$ is won by the two purposes. They are updating knowledge and conducting discussions. Not only $7 \%$ of students gather information for making presentation for their studies. As well as 5\% of students gather information for answering questions related to their subject areas and $3 \%$ of students collect information to fulfill their thinking and observation purposes. The verse case is that very few students gather information for their research work. It is not a good quality for higher education institute.

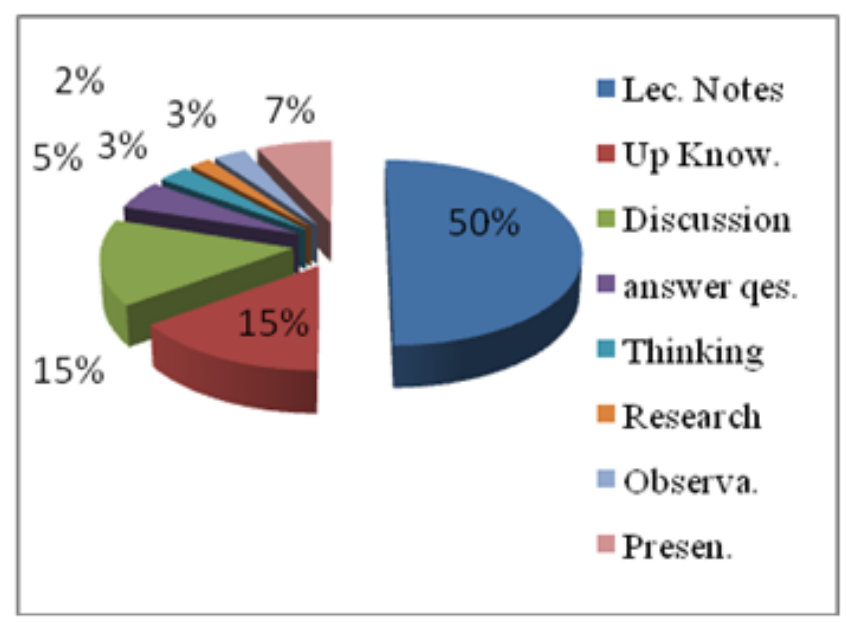

Figure 4. Purpose of gathering information

\subsection{Favorite Language}

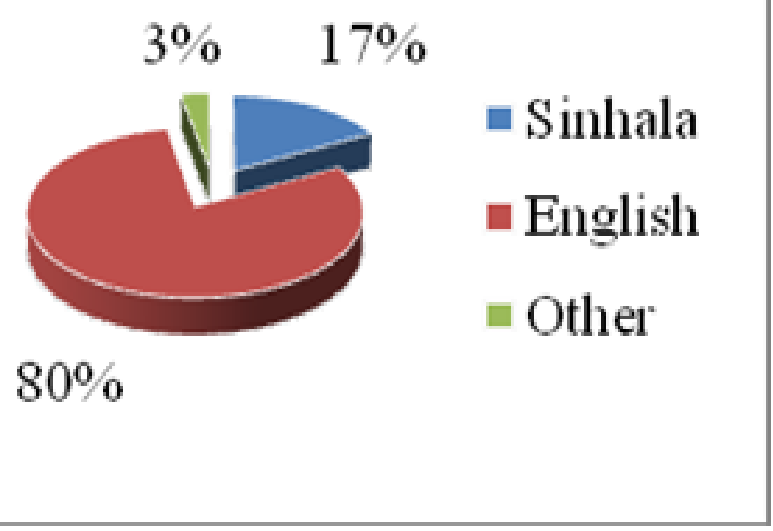

Figure 5. Favorite language for information gathering

According to the figure $5,80 \%$ of the students search their information by English Language. 17\% of students like Sinhala language and 3\% of students like other language for collecting information. Most of syllabus and lectures conduct in English language in the CINEC campus. So that most of students used to use English language as information gathering language.

\subsection{Information Media}

Above figure 6 display that $50 \%$ of the students use the library as their information media. It is saying that the library is the heart of the university system. CINEC campus also proved the above saying. But this is not a good eminence for the library. The reason for that is $50 \%$ of students use other media to collect information for their studies. $25 \%$ of 
students use their personal collections and $15 \%$ of students use IT based sources like CD, DVD, databases, e-books for their educational purposes. As such $5 \%$ of students use discussions and other media for fulfill their educational needs.

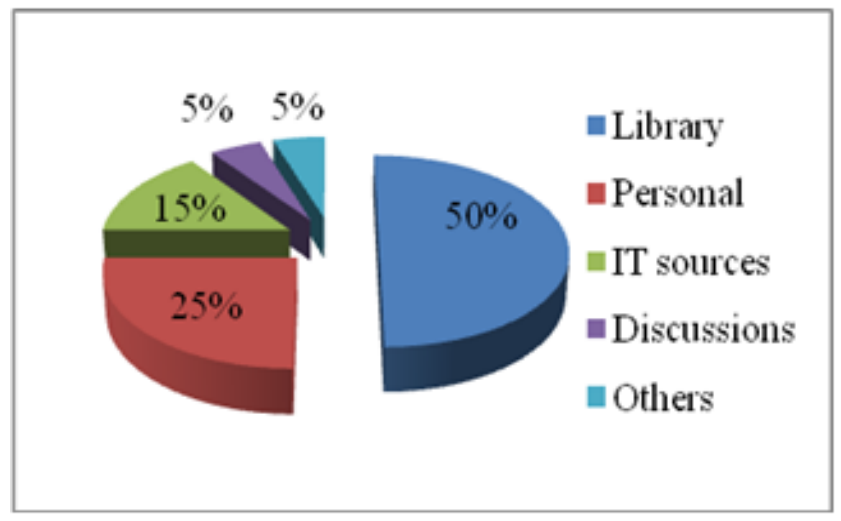

Figure 6. Information media to gather information

\subsection{Internet Usage for Information Gathering}

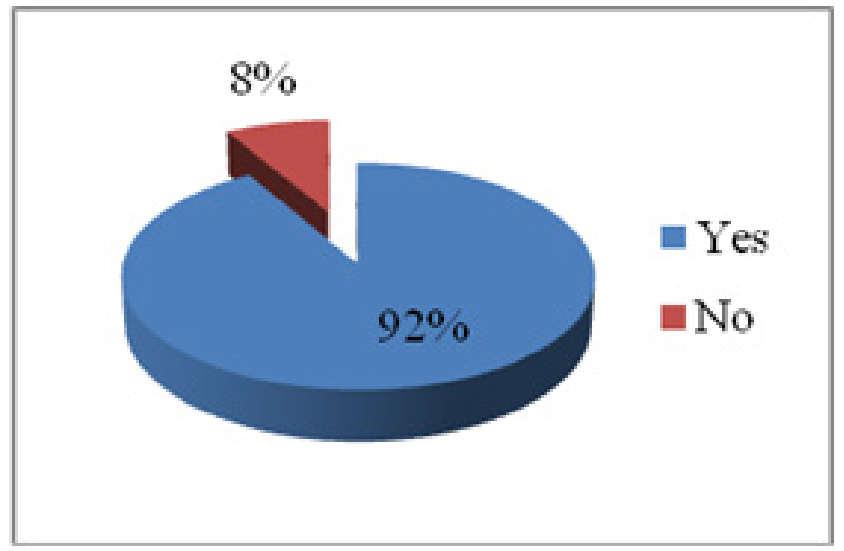

Figure 7. Internet usage for information gathering

According to figure $7,92 \%$ of the students use internet to gather information and they addicted to use internet daily. Only $8 \%$ of students do not use internet for their studies. In present new generation normally depend on modern technology like computers, internet, i-phones etc.

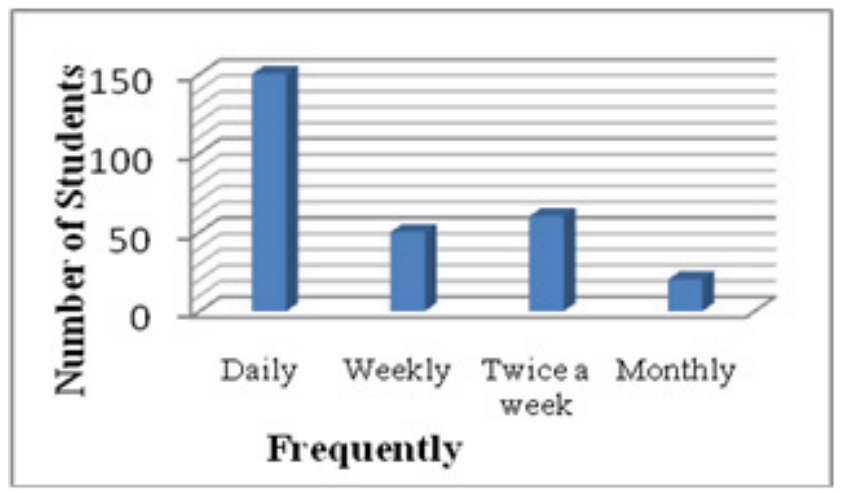

Figure 8. Usage of CINEC Library

\subsection{Usage of CINEC Library}

Figure 8 described that $63 \%$ of the students visit CINEC library daily. In addition to above most of students visit the library even once a month. That is a good situation for the higher education institute.

\subsection{Purpose of the Library Visiting}

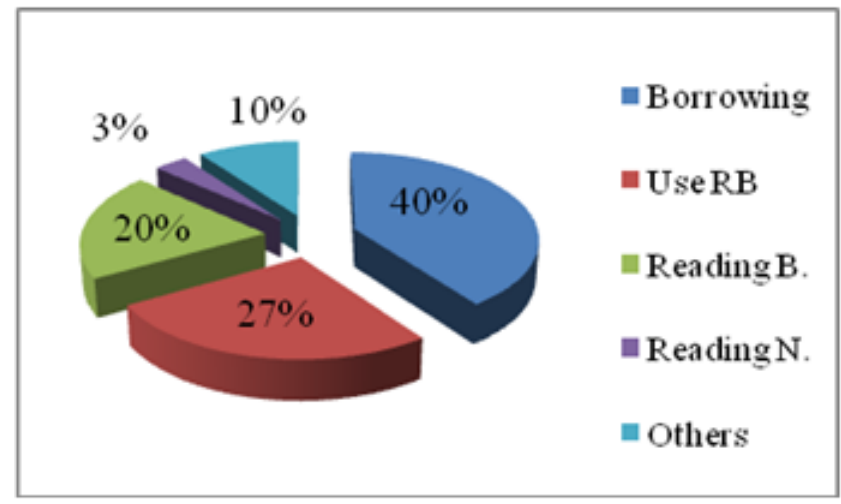

Figure 9. Purpose of the library visiting

$40 \%$ of the Students visit the library for borrowing books. $27 \%$ of students normally visit the library to use reference books related to their subjects. Orderly $20 \%, 10 \%$ and $3 \%$ get for reading books, reading novels and other purposes.

\subsection{OPAC Usage}

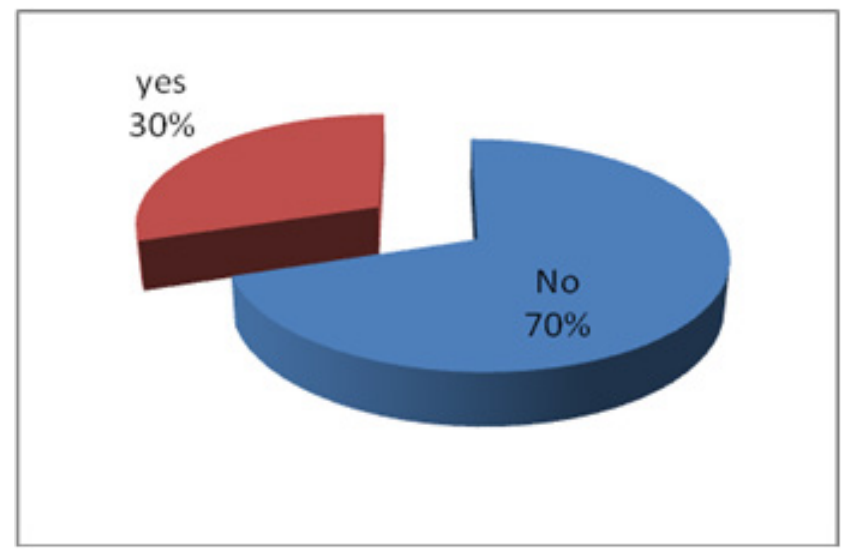

Figure 10. Usage of OPAC

$70 \%$ of students do not know how to use the OPAC. So they get introduction from the staff members to find books. Besides users of CINEC campus used to use shelf reading method to find a book.

\section{Discussion}

According to the results of this research, the majority of students visit the library to fulfill their information needs. But this condition can not apply for the Sweden context. General practitioners in Sweden cannot depend on 
conventional medical libraries for their urgent information needs and they try to keep their personal collections updated and well organized. This is a result of research on Information needs and information seeking behavior in primary Health Care conducted by Timpka, Ekstrom and Bjurulf (1).

As an educational institute, $50 \%$ of students gather information for making their lecture notes. Only 3\% of students gather information for research work. But Pure Scientists in the University of Sri Lanka gather information for their research work. They normally addicted to collect data from journals, periodicals and abstract of the journals (Illeperuma, 1998)(3). But there isn't a trend of research work in the CINEC campus as a higher education institute. Over and above Pure Scientists in Sri Lanka university also gather information for their research work and they widely used periodicals, journals and journal abstract to get current information (Illeperuma, 1998)(3).

Majority of Students in CINEC campus addicted to use the institute's library for their educational work. This situation is different from the period of 90's. Environmental Scientists in Sri Lanka normally used their own libraries or personal libraries for their research work because of the lack of services and resources provided by the institutional library (Gamage, 1990) (4).

$95.6 \%$ of trainee teachers in State of Johor, Malaysia relied heavily on lecture notes as their most frequent source of information. This condition is similar with student in CINEC Maritime campus. Most students in CINEC campus also depend on their lecture notes. Normally they gather information to make their lecture notes completed (Shanmugam, 1999) (8).

\section{Conclusions}

In here the researcher tries to bring findings of this study about information needs and information seeking behavior of students in higher education institutes. Results revealed that $50 \%$ of the students gather information for preparing their lecture notes. They collect information for updating their knowledge and having for discussions. Most of students in CINEC campus did not pay their attention on research work. They use information sources only for their studies. But as a students in higher education institute, they should pay their attention on research work. Unfortunately students in CINEC campus do not give heavy contribution for development of the country.

CINEC Maritime campus library is the most frequently used place of a best access for information gathering of the students. Normally they depend on the collection of the CINEC library. Besides $80 \%$ of the students search their information in English. Students of CINEC maritime campus are used English language for their studies than Sinhala language. It is prove that most of student in private higher education institutes are known English language well and they use English for their studies. In addition $63 \%$ of the students visit CINEC library daily to borrow books for their studies. But these students do not know how to find a book from the library. Normally they ask help from the staff of the library.

According to above findings, the researcher recommended following suggestions to improve the quality of library of the CINEC maritime campus.

- Using Information Technology (IT) is improved through students when they retrieval information for their information needs.

- $\quad$ Library should conduct Information Programme (IL) for students.

- Introduce new library services to increase library usage further more. Such as, referral services, help desk services and literature review.

\section{Acknowledgements}

I wish to express my sincere gratitude to Ms. Poornika Sndhamali Chandrawansa and staff of the CINEC maritime campus for helping me to collect data for the research. I would like to convey my sincere gratitude for all who help me lot for this research. Further, I also thankful to my husband, parents, brothers, sisters and my friends for their dedication and assistance. Finally, I wish to express my sincere thanks to all that gave me support and encouragement in numerous ways to make this effort a success.

\section{REFERENCES}

[1] Timpka, Toomas, Ekstrom, Marie \& Bjurulf, Per (1989), Information needs and information seeking behavior in primary health care, Scand J Prim Health care [Online], 7, p.p. 105-109, Available at: informahealthcare.com, [accessed 09 March 2012]

[2] Ellis, D., Cox, D. \& Hall, K. (1993) A comparison of the information seeking patterns of researches in the physical and Social Sciences, Journal of Documentation, 49 (4), p.p. 356-369.

[3] Illeperuma, Sriyani (1998), Final report on information needs and information gathering behavior of researchers in the Humanities, Social Science, Language studies \& Culture (Art scholars) in the universities of Sri Lanka, Colombo, NARESA.

[4] Gamage, U. G. C. C. (1999), Information needs and information seeking behavior of Environmental Scientists in Sri Lanka, M.S.Sc. thesis, University of Kelaniya.

[5] Zawawi, Salina \& Majid, Shaheen (2001), The information needs and seeking behavior of the IMR Biomedical Scientists, Malaysia, Journal of Library \& Information Science, [Online], 5 (1), p.p. 25-41, Available at: [accessed 09 March 2012]

[6] Jorosi, Boemo Nlayidzi (2006), The information needs and information seeking behavior of SME managers in Botswana 
(SME- Small \& Medium sized Enterprises), Libri, [Online], 56, p.p. 97-107, Available at: [accessed 09 March 2012]

[7] Saleh, Adam Gambo \& Lasisi, Fatima Ibrahim (2011), Information needs and information seeking behavior of rural women in Borno state, Nigeria.
[8] Shanmugam, A. (1999), Information seeking behavior of trainee teachers in selected teacher training colleges in Malaysia, Malaysian Journal of Library \& Information Science, Vol.4, No.1. 1-26p.p. 